\title{
Mortality caused by aqueous extract of the leaves of Datura stramineus to goat biting louse, Bovicola caprae (Phthiraptera)
}

\author{
Archna Rashmi, Aftab Ahmad and A. K. Saxena* \\ Department of Zoology, Govt. Raza P.G. College, Rampur (U.P.), INDIA \\ *Corresponding author. E-mail: akscsir@rediffmail.com \\ Received: May 28, 2017; Revised received: July 29, 2017; Accepted: January 12, 2018
}

\begin{abstract}
Extensive and indiscriminate use of organic lousicides is leading to environmental hazards i.e. persistence of residues, development of resistance and targeting of non-target beneficial organism. Hence, phytotherapy is emerging as effective tool for louse control, due to ecofriendly and biodegradable nature of plant extracts. In the present study the mortality and repellency caused by five concentration of aqueous extract of the leaves of commonly available Datura stramineus were tested against goat biting louse, Bovicola caprae. Fifteen percent concentration of extract prepared from leaves of aforesaid plant imparted $77 \%$ mortality and $66 \%$ repellency to goat biting louse.
\end{abstract}

Keywords: Biting lice, Bovicola caprae, Datura stramineus, Goat louse, Phthiraptera

\section{INTRODUCTION}

Effective lice control is no longer a matter of replicate application of synthetic pesticides as it harms the nontarget beneficial organisms, contaminates food and feed, apart from its economic implications. Extensive and indiscriminate use of organic pesticides generally creates environmental hazards. Pesticidal formulations based on chemicals from plants have attained particular attention because of specificity to insect pests, their biodegradable nature and potential for commercial application as natural toxicant, repellent or behaviour modifiers. The herbal formulations launched by different pharmaceutical companies (Pestoban-D, Nimbitor, $\mathrm{AV} / \mathrm{EPP} / 14$ and Ectozee) have been tested against ectoparasites of poultry, dogs, buffaloes and cattle (Das et al., 1993; Maske and Bhilegaonkar, 1995, 96; Bhilegaonkar and Maske, 1997; Maske et al., 2000)

The lousicidal properties of few plant extracts have been tested against poultry lice (Kumar et al 2002a, b, 2003; Khan et al., 2008,Brigid et al., 2015, Al-musawi, 2017). Workers likes Abdel- Ghaffar et al. (2012), Campli et al. (2012) and Yones et al. (2016) have tested the lousicidal properties of certain plant extracts against human head lice. The lousicidal efficacy of camphor oil has been tested against a pigeon louse (Khater et al., 2013). Effect of garlic (Allium setivum) on the goat lice Bovicola caprae has been studied by Lakshmanan et al. (2013). Kosale et al. (2009) has also tested the licicidal activity of certain plants. The present report supplements information on the efficacy of aqueous extract prepared from the leaves of Datura stramineus, against goat biting louse, Bovicola caprae.

\section{MATERIALS AND METHODS}

For the present study healthier lice (Bovicola caprae) were collected from lousy goats, with the help of wetted camel hairbrush. The leaves of the common plant Datura stramineus were collected from neighboring localities. For the preparation of extract, the leaves of plants were dried in shade, at room temperature. The dried materials were cut into small pieces and then grounded (with the help of electric/ iron grinder) into fine powder. The powder was soaked in water in weight to volume ratio ranging from $1: 3$ to $1: 5$ and kept for 72 hrs., at room temperature. The extract was filtered through Whatman's filter paper no. 1 (3 times). The water was removed from the extracts by evaporation with the help of rotovap. The residue of the aqueous extract of leaves so prepared was stored in the freezer, till testing. In-vitro filter paper bioassay (mortality and repellency) of the lousicidal activity of extract (untreated filter paper as control) was conducted on the lines adopted by Kumar et al. (2002a) and Khan et al. (2008). One way Annova test was applied to determine the significance of differences in the mortality rates and exposure time.

\section{RESULTS AND DISCUSSION}

The percentage mortality caused by different concentrations of the extract of Datura leaves to goat biting louse, Bovicola caprae after 6 hrs., 12 hrs., 24 hrs. and $48 \mathrm{hrs}$. intervals has been shown in Fig. 1. Five percent concentration of Datura leaves caused $35.2 \%$ mortali- 

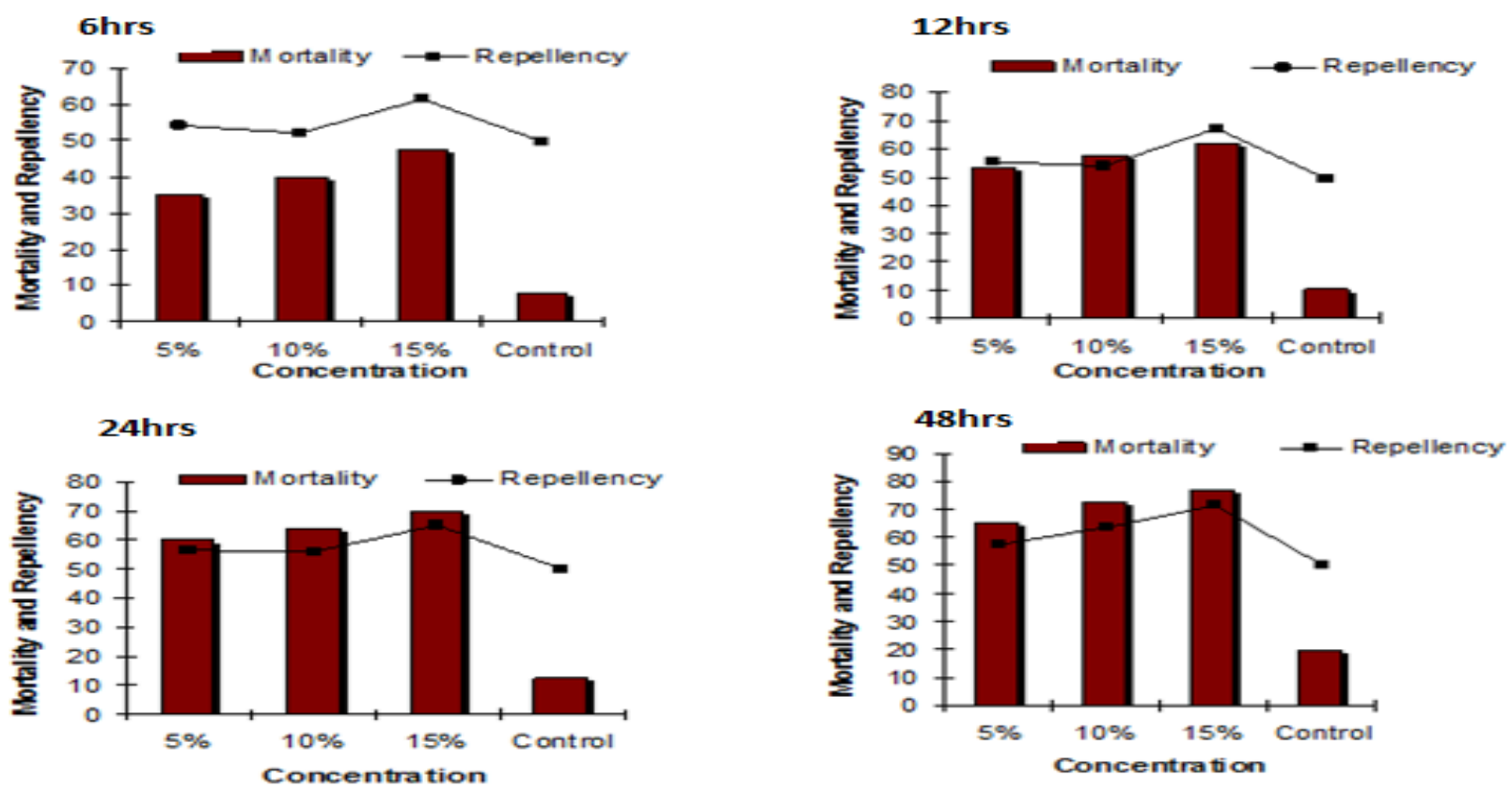

Fig. 1. Showing percent mortality (\%) and repellency (\%) of goat biting louse, Bovicola caprae against three concentration of Datura leaves (Datura stramenium) extract, with respect to exposure time.

ty in 6 hrs., $53.1 \%$ in 12 hrs., $60.2 \%$ in 24 hrs. and $65.4 \%$ in 48 hrs. Likewise, $10 \%$ concentration of extract caused $40.2 \%$ mortality after 6 hrs., $57.3 \%$ after 12 hrs., $63.8 \%$ after 24 hrs. and $72.6 \%$ after 48 hrs. Lastly, the percent mortality caused by $15 \%$ concentration at $6 \mathrm{hrs}$., $12 \mathrm{hrs}$., $24 \mathrm{hrs}$. and $48 \mathrm{hrs}$. remained $47.6 \%, 62.3 \%, 70.1 \%$ and $76.78 \%$, respectively. The corresponding values of percentage mortality in control group were $7.67 \%, 10.33 \%, 12.29 \%$ and 19.33 $\%$. The differences in the mortality rates imparted by the extracts were significant (at 0.001 level) with respect to concentration but not the exposure time (one way Anova). Percentage repellency caused by 5\%, $10 \%$ and $15 \%$ concentrations of Datura extract at 6 , 12, 24, and 48 hrs. are shown in Fig. 1. Mean value of repellency caused by $5.0 \%$ preparation remained $55.7 \%$. Likewise, the average values of percentage repellency shown by 10 and $15 \%$ preparation of Datura leaves extract remained $56.4 \%$ and $66.3 \%$,respectively. Few workers have tried to test the lousicidal potential of formulations launched by selected pharmaceutical companies. viz. Nimbitor (Maske et al., 2000), Pestoban-D (Das et al., 1993), Ectozee (Maske and Bhilegaonkar, 1995; 96) and AV/EPP/14 (Bhilegaonkar and Maske, 1997). Lousicidal properties of Citrus vulgaris, Azadirachta indica, Adhatoda vessica, Argemone maxicana and Cassio fistula have been tested against tropical hen louse, Lipeurus lawrensis tropicalis (Kumar et al., 2002a). The aqueous extract prepared from the leaves of Azadirachta indica imparted maximum mortality $(80 \%)$ and repellency $(73 \%)$ to a $L$. lawrensis tropicalis Furthermore, lousicidal potentials of leaf and seed extract of Zanthoxylum alatum have also been tested (Kumar et al., 2002b, 03). An isolated fraction of the acetone extract of $Z$. alatum imparted $80 \%$ motality and $96 \%$ repellency to L. lawrensis tropicalis (Kumar et al., 2002b). Likewise, the acetone extract prepared from seed extract of same plant caused $100 \%$ mortality to aforesaid louse in 12 hours (at 1:1 concentration). The crude Mentha (Mentha piperita) oil diluted with methanol also caused $100 \%$ motality to a L. lawrensis tropicalis in 48 hours (Khan et al., 2008). Khater et al. (2013) found that 1\% camphor oil and d phenothrin killed the tested pigeon lice, Columbicola columbae within one hour. Likewise, Almusawi (2017) noted the potent anti-lice property of Ziziphus mauritiana alkaloids and Eucaylptus camaldulensis against poultry lice Menacanthus stramineus and recorded its LC 50 values as 3.687and 1.045, respectively. Leaves of Datura appear to contain an ingredient having lousicidal property as its extract imparted $77 \%$ mortality and $66 \%$ repellency to goat bitting louse (at $15 \%$ concentration, in $48 \mathrm{hrs}$.). Plants extract imparting more than $75 \%$ mortality to pest attract the attention of workers for futher screening (seperation of fractions present in its extract by TLC, testing of its active ingredient for licicidal potential, followed by molecular characterization)

\section{Conclusion}

Plants contain a wide range of bioactive compounds having potent pesticidal properties. They are easily extractable, ecofriendly, biodegradable and do not harm non target organism. The aqueous extract prepared from leaves of a commonly available plant Datura stramineus imparted $77 \%$ motality to goat biting 
louse, Bovicola caprae (at $15 \%$ concentration in 48 hrs.). Further separation of its active ingredients, its testing and characterization may help in developing a lousicide.

\section{ACKNOWLEDGEMENTS}

The authors are thankful to the Principal, Govt. Raza P. G. College, and Rampur, for laboratory facilities, and to the UGC, New Delhi, India for providing financial support to Archna Rashmi, in the form Rajeev Gandhi National Fellowship.

\section{REFERENCES}

Abdel-Ghaffar, F., Al-Quraishy, S., Al-Rasheid, K. and Mehlhorn, H. (2012). Efiicacy of a single treatment of head lice with a neem seed extract: an in vivo and in vitro study on nits and motile stage. Parasitol. Res., 110: 277-280.

Al-musawi, M. M. (2017). Evaluation of Lousicidal activity of Ziziphus mauritiana alkaloids and Eucaylptus camaldulensis terpenoids leaves extracts in chickens. Al-kufa univ. Jour. Biol., 9:1-9.

Bhilegaonkar, N. G. and Maske, D. K. (1997). Efficacy of herbal compound AV/EPP/14 against ectoparasites of dogs. Indian Vet. J., 74(10):869-870.

Brigid, M., Joan, S., Ralph, A. E. and Alec, C. G. (2015). Common lice and mites of poultry: Identification and treatment. ANR publication,University of California, 1-7

Campli, E., Di Bartolomeo, S., Pizzi, P., Giulio, M., Grande, R., Nostro, A. and Cellini, L. (2012). Activity of tea tree oil and nerolidol alone or in combination against Pediculus capitis (head lice) and its eggs. Parasitol. Res., 111:1985-1992.

Das, S. S., Bhatia, B.B and Kumar, A. (1993). Efficacy of Pestoban "D" against common poultry lice. Indian Vet. Res., 2(2):25-26.
Khan, V., Ahmad, A., Gupta, N. and Saxena, A.K. (2008). Lousicidal properties of Mentha oil against tropical hen louse. Indian Vet. J., 85:323-324.

Khater, H. F., El-shorbagy, M. M. and Seddiek, S. A. (2013). Lousicidal efficacy of camphor oil D- phenothrin and deltametrin against slender pigeon louse Columbicola columbae. Int. J. Vet. Sci. 2:7-13.

Kosale, S. B., Fursule, R. A. and Patel, R.C. (2009). Investigations of licicidal activity of some plants from Satpuda hills. Int. J. Pharm. Technol. Res., 1(3):564-567.

Kumar, S., Singh, S. K., Baslas, R. K., Ghildiyal, J. C. and Saxena, A. K. (2002a). Lousicidal properties of few aqueous plant extracts. Indian Vet. J., 79:1136-1140.

Kumar, S., Singh, S. K., Baslas, R.K.; Ghildiyal, J.C. and Saxena, A.K. (2002b). Isolation and characterization of lousicide from the leaves of Zanthoxylum alatum (Family : Rutaceae). Rivista di Parassitol, 19(63):137140

Kumar, S., Singh, S. K., Ghilidyal, J. C., Baslas, R. K. and Saxena, A. K . (2003). The lousicidal potential of the seed extract of Zanthoxylum alatum. Indian Vet. J., 80: 848-850.

Lakshmanan, B., Radhika, R., Sreekrishnan, R. and Subramanian, H.(2013). In vitro studies on the effect of Allium sativum (garlic) on Damalinia caprae. J. Vet. Anim. Sci, 44:61-62.

Maske, D.K. and Bhilegaonkar, N.G. (1995). Field trials of "Ectozee" against ectoparasite of cattle and dogs. Indian J. Indig Med., 17(2):31-33.

Maske, D.K. and Bhilegaonkar, N.G. (1996). In vitro trials of "Ectozee" against ectoparasite of cattle and dogs. Indian J Indig Med., 18(1):67-69.

Maske, D. K., Kolte, S. W. and Jangda, C. R. (2000). Efficacy of neem based compound "Nimbitor" against ectoparasites of cattles. Indian Vet. J., 77:103-106.

Yones, D., Bakir, H. and Bayoumi, S. (2016). Chemical composition and efficacy of some selected plant oils against Pediculus humanus capitis in vitro. Parasitol. Res., 115(8):3209-3218. 